\title{
Evaluation of the prevalence of glucose metabolism disorders in patients with dyspepsia
}

\section{ABSTRACT}

Introduction. As estimated by IDF, by 2045 there will be about 628 million of people living with diabetes, of which $87-91 \%$ will have type 2 diabetes. Therefore, early diagnosis of diabetes is very important, and currently only $\mathbf{4 - 5 0 \%}$ of cases are diagnosed early enough. The aim of the study was to establish whether patients with dyspepsia may potentially be a group at high risk of developing diabetes in which screening for glucose metabolism disorders would be particularly important. Material and methods. The study included 59 women $(65.5 \%)$ and 31 men (34.5\%), with a mean age of 36 years, hospitalized in order to perform gastroscopy due to symptoms of dyspepsia. All patients were apparently healthy, without the history of cardiovascular diseases or diabetes, and were non-smokers. The patients were subjected to laboratory tests (random blood glucose, oral glucose tolerance test [OGTT], lipid profile, C-reactive protein level), gastroscopy and a rapid urease test for detection of active Helicobacter pylori infection. Body mass index (BMI) was also calculated. Subjects with abnormal results of the oral glucose tolerance test (OGTT) were assigned to the group with glucose metabolism disorders and the remaining subjects to the group without glucose metabolism disorders.

Address for correspondence:

lek. Anna Bryczkowska

II Klinika Kardiologii i Chorób Wewnętrznych, Collegium Medicum,

Wydział Lekarski, Uniwersytet Warmińsko-Mazurski w Olsztynie

ul. Warszawska 30, 10-082 Olsztyn

Phone: +48790250290

e-mail: abryczkowska@wp.pl

Translation: lek. Małgorzata Kamińska

Clinical Diabetology 2018, 7, 6, 253-258

DOI: $10.5603 /$ DK.2018.0027

Received: 01.07.2018

Accepted: 05.12.2018
Statistical analysis of the obtained research results was carried out using the Statistica 7.0 PL software. Results. The subjects were divided into two subgroups based on the result of the oral glucose tolerance test, adopting the principles of diagnosing carbohydrate metabolism disorders according to the Diabetes Poland. The group with glucose metabolism disorders included 33 patients (36.5\%): 5 subjects $(5.5 \%)$ with impaired fasting glucose, 20 patients (22\%) with impaired glucose tolerance and 8 patients $(9 \%)$ with diabetes. The remaining 57 (63.5\%) patients had normal results of OGTT and were assigned to the group without glucose metabolism disorders. The mean BMI in the whole examined population was $26.7 \mathrm{~kg} / \mathrm{m}^{2}$. Patients with glucose metabolism disorders (GMD) had a significantly higher BMI $\left(31.1 \mathrm{~kg} / \mathrm{m}^{2}\right)$. The levels of total cholesterol, LDL cholesterol and TG were higher in patients with GDM; however, the difference was not statistically significant. Random blood glucose values were significantly higher in the group with GDM, but no patient had random blood glucose $\geq 200 \mathrm{mg} / \mathrm{dL}$. The $\mathrm{HbA}_{1 \mathrm{c}}$ value was significantly higher in the GMD group. Also, the C-reactive protein (CRP) level was significantly higher in the group of patients with GMD than in the group of healthy subjects. All patients underwent gastroscopy and abnormal results were found in 41 patients ( $45.5 \%$ of total study population) - in $67 \%$ in the group with GMD and $33 \%$ in the group without GDM. The most frequent pathology was Helicobacter pylori infection (25.5\%). This infection was more prevalent in the group with GDM (45\%) than in the group without GDM (14\%). In addition, gastritis, gastric cancer, gastro-esophageal reflux, hiatal hernia, and gastric polyps were found, without significant differences between the subgroups. 
Conclusions. Over $1 / 3$ of the subjects with dyspepsia had prediabetes or diabetes; therefore, it seems that this group of patients should be screened for glucose metabolism disorders. High prevalence of GMD among patients with dyspepsia indicates potential benefits of performing OGTT in this group of patients. Gastrointestinal symptoms may be an early manifestation of glucose metabolism disorders. There is a correlation between Helicobacter pylori infection and the presence of glucose metabolism disorders. (Clin Diabetol 2018; 7, 6: 253-258)

Key words: type 2 diabetes, glucose metabolism disorders, dyspepsia

\section{Introduction}

Type 2 diabetes is considered as a social disease and its prevalence is constantly growing. It is estimated that in 2045 there will be about 628 million people with diabetes. Currently, only $40-50 \%$ of cases are properly diagnosed, which enables the implementation of effective treatment. In the remaining $50-60 \%$ diabetes is undiagnosed, which - despite the oligosymptomatic course - leads to gradual development of complications. Due to the often asymptomatic course of the early stages of type 2 diabetes, screening is of key importance for early diagnosis, especially in groups of patients at increased risk of carbohydrate disorders.

Dyspeptic symptoms are very common. Recent studies show that dyspepsia is more prevalent in patients with diabetes than in non-diabetic subjects. Therefore, it has been hypothesized that the presence of dyspeptic symptoms could be useful in identifying a group of patients with higher risk of asymptomatic glucose metabolism disorders, including prediabetes. Screening these patients for glucose metabolism disorders may result in early diagnosis and consequently early implementation of treatment, thus protecting patients from silent complications of diabetes and even diabetes itself.

The aim of the study was to establish whether patients with dyspepsia may potentially be a group at high risk of developing diabetes in which screening for glucose metabolism disorders would be particularly important.

\section{Material and methods}

The study included 90 people, 59 women (65.5\%) and 31 men (34.5\%), with an mean age of 36 years, hospitalized in the 2nd Department of Cardiology and Internal Diseases of the University Clinical Hospital in Olsztyn in order to perform gastroscopy due to symp- toms of dyspepsia. Included in the study were apparently healthy patients, without the history of cardiovascular diseases or diabetes, and were non-smokers.

Dyspepsia was defined as the presence of at least 1 of the following symptoms: epigastric pain, feeling of fullness, epigastric discomfort, and eructation [1]. The examined patients had the symptoms of dyspepsia for at least 3 months. All patients underwent physical examination including blood pressure measurement and the calculation of the body mass index (BMI), according to the Quetelet formula, where $\mathrm{BMI}=$ body weight $[\mathrm{kg}] /$ height $\left[\mathrm{m}^{2}\right]$.

Following laboratory tests were performed in each patient:

- glycemic profile:

- glycated hemoglobin $\left(\mathrm{HbA}_{1 \mathrm{c}}\right)$,

- blood glucose at admission (random),

- blood glucose on fasting state and 2 hours after administration of $75 \mathrm{~g}$ glucose (oral glucose tolerance test, OGTT). On the basis of OGTT, the following glucose metabolism disorders (GMD) were diagnosed:

1) impaired fasting glucose (IFG),

2) impaired glucose tolerance (IGT),

3) diabetes mellitus (DM),

- lipid profile: total cholesterol, LDL cholesterol, HDL cholesterol, triglycerides;

- C-reactive protein (CRP).

All laboratory tests were performed using standard methods.

Gastroscopy was carried out using Olympus GIF-Q165 and GIF-Q180 apparatus, by a qualified endoscopist, certified in panendoscopy by the Polish Society of Gastroenterology.

A rapid urease test was used to diagnose Helicobacter pylori infection.

The study was approved by the Bioethical Committee of the Warmia and Mazury Regional Medical Chamber in Olsztyn on 4th December 2012. It included analysis of results of standard diagnostic test and voluntary and anonymous surveys.

\section{Statistical analysis}

Statistical analysis of the test results was carried out using the Statistica 7.0 PL software. To verify hypotheses about the existence or absence of relationship between categorized variables, the Pearson 2 test and $2 \mathrm{NW}$ test (the highest reliability) were used. To compare the mean values of measurable variables, the Student's t-test or the nonparametric Mann-Whitney $U$ test were used (for comparisons between two groups). The Chi-square test was used to compare the qualitative variables using cross-tabulation table. The Schapiro-Wilk test was used 
to analyze measurable variables that were non-normally distributed. 95\% confidence intervals $(95 \% \mathrm{Cl})$ were determined for the analyzed values. P-values $<0.05$ were considered as statistically significant.

\section{Results}

The study included 90 people with a mean age of $36.1 \pm 12.5$ years (59 women [65.5\%] and 31 men [34.5\%], hospitalized in the 2nd Department of Cardiology and Internal Diseases of the University Clinical Hospital in Olsztyn due to dyspepsia.

The subjects were divided into two subgroups based on the result of the oral glucose tolerance test (OGTT), adopting the principles of diagnosing carbohydrate metabolism disorders according to the Diabetes Poland. The group with glucose metabolism disorders included 33 patients (36.5\%): 5 subjects (5.5\%) with impaired fasting glucose, 20 patients $(22 \%)$ with impaired glucose tolerance and 8 patients ( $9 \%$ ) with diabetes. The remaining 57 (63.5\%) patients had normal results of OGTT and were assigned to the group without glucose metabolism disorders (Figure 1).

The mean BMI in the whole examined population was $26.7 \mathrm{~kg} / \mathrm{m}^{2}$. Patients with glucose metabolism disorders (GMD) had a significantly higher BMI $\left(31.1 \mathrm{~kg} / \mathrm{m}^{2}\right)$ compared to those without GDM $\left(24.1 \mathrm{~kg} / \mathrm{m}^{2}\right)$; $\mathrm{p}=0.007$. The levels of total cholesterol, LDL cholesterol and TG were higher in patients with GDM; however, the difference was not statistically significant Table 1).

Random blood glucose values were significantly higher in the group with GDM than in healthy subjects (86.9 mg/dL vs. $93.03 \mathrm{mg} / \mathrm{dL}$, respectively; $\mathrm{p}<0.017$ ). No patient had random blood glucose $\geq 200 \mathrm{mg} / \mathrm{dL}$.

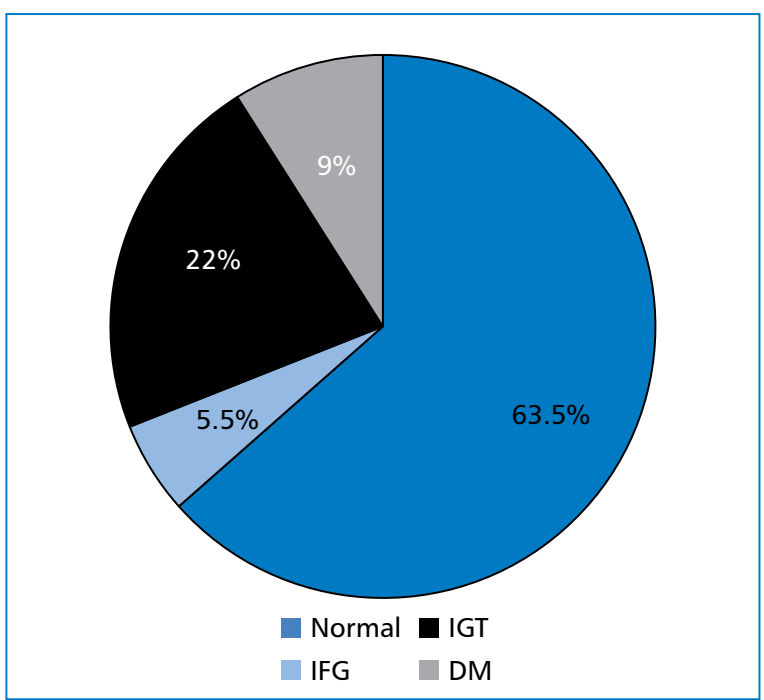

Figure 1. The prevalence of glucose metabolism disorders in patients with dyspepsia. According to the Diabetes Poland guidelines: random blood glucose $\geq 200 \mathrm{mg} / \mathrm{dL}(\geq 11.1$ $\mathrm{mmol} / \mathrm{L})$, measured at the time when symptoms of hyperglycemia are presented - diabetes mellitus (DM); fasting blood glucose: $70-99 \mathrm{mg} / \mathrm{dL}$ - normal fasting blood glucose, $100-125 \mathrm{mg} / \mathrm{dL}$ - impaired fasting glucose (IFG), $\geq 126 \mathrm{mg} / \mathrm{dL}$ on two occasions - DM; blood glucose at 120 minutes of oral glucose tolerance test (OGTT): $<140 \mathrm{mg} / \mathrm{dL}$ - normal glucose tolerance (NGT), $140-199 \mathrm{mg} / \mathrm{dL}$ - impaired glucose tolerance (IGT), $\geq 200 \mathrm{mg} / \mathrm{dL}(11.1 \mathrm{mmol} / \mathrm{l})$ - DM [20]. IFG impaired fasting glucose; IGT — impaired glucose tolerance; DM - diabetes mellitus

The $\mathrm{HbA}_{1 \mathrm{c}}$ value was significantly $(\mathrm{p}<0.024)$ higher in the GMD group and amounted to $5.5 \%$ (Figure 2).

In the group of patients with GMD C-reactive protein (CRP) level was $1.3 \mathrm{mg} / \mathrm{L}$ - significantly $(\mathrm{p}<0.003)$ higher than in the group without GDM (Figure 3).

Table 1. General characteristics of the examined group according to presence of absence (healthy subjects) of glucose metabolism disorders (GMD)

\begin{tabular}{|c|c|c|c|c|}
\hline \multirow[t]{3}{*}{ Parameter } & \multicolumn{4}{|c|}{ Study groups n (\%) } \\
\hline & Total $90(100 \%)$ & Healthy subjects & GMD 33 (37\%) & $\mathbf{p}$ \\
\hline & \multicolumn{3}{|c|}{$57(63 \%)$} & \\
\hline Age [years, SD] & $36.1 \pm 12.5$ & $35.2 \pm 12.5$ & $37.7 \pm 12.6$ & 0.367 \\
\hline $\mathrm{BMI}\left[\mathrm{kg} / \mathrm{m}^{2}\right][S D]$ & $26.7 \pm 8.3$ & $24.1 \pm 4.6$ & $31.1 \pm 11.1$ & 0.007 \\
\hline Total cholesterol [mg/dl] [SD] & $189.1 \pm 42.0$ & $184.2 \pm 42.0$ & $197.4 \pm 41.3$ & 0.154 \\
\hline LDL cholesterol [mg/dl] [SD] & $107.9 \pm 32.1$ & $105.9 \pm 31.3$ & $111.3 \pm 33.7$ & 0.445 \\
\hline HDL cholesterol [mg/dl] [SD] & $55,0 \pm 15.4$ & $55.7 \pm 14.3$ & $53.9 \pm 17.4$ & 0.59 \\
\hline Triglycerides [mg/dl] [SD] & $109.8 \pm 57.9$ & $97.6 \pm 43.1$ & $130.7 \pm 73.3$ & 0.069 \\
\hline Random glycemia [mg/dl] [SD] & $89.2 \pm 11.7$ & $86.9 \pm 11.4$ & $93.0 \pm 11.5$ & 0.017 \\
\hline Fasting glycemia [mg/dl] [SD] & $90.2 \pm 14.2$ & $86.4 \pm 10.0$ & $96.7 \pm 17.7$ & 0.000 \\
\hline Glycemia $120 \mathrm{~min}$ post-load [mg/dl] [SD] & $130.7 \pm 45.9$ & $106.5 \pm 20.63$ & $172.6 \pm 47.6$ & 0.000 \\
\hline $\mathrm{HbA}_{1 \mathrm{c}}(\%)$ & $5.4 \pm 0.6$ & $5.3 \pm 0.4$ & $5.6 \pm 0.5$ & 0.005 \\
\hline CRP [mg/l; SD] & $2.2 \pm 3.2$ & $1.3 \pm 1.7$ & $3.7 \pm 4.4$ & 0.003 \\
\hline
\end{tabular}

SD — standard deviation; BMI - body mass index; CRP - C-reactive protein 


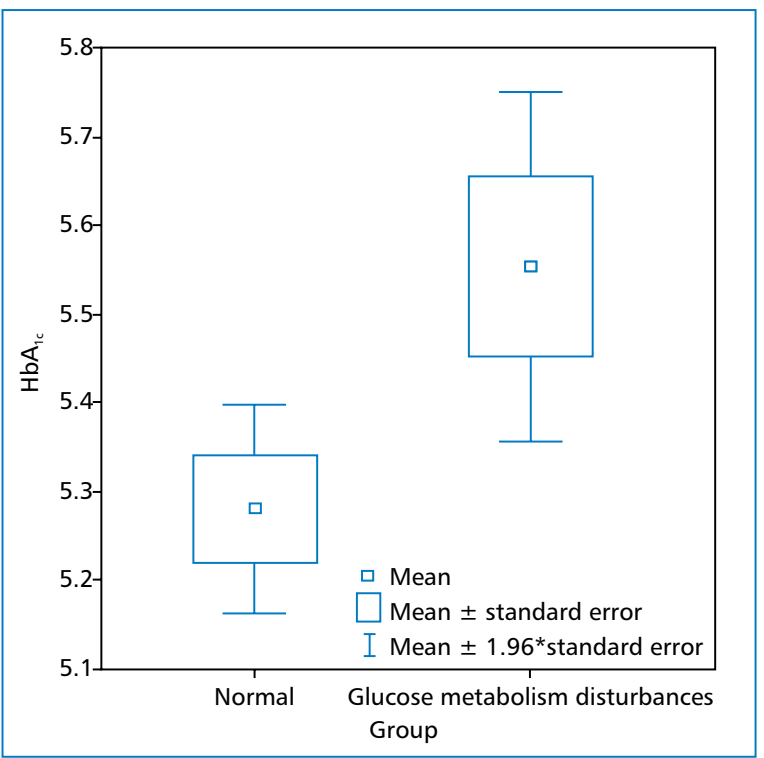

Figure 2. Mean $\mathrm{HbA}_{1 c}$ values in patients with glucose metabolism disorders (GMD) and in subjects with normal blood glucose. Mean $\mathrm{HbA}_{1 c}$ was significantly higher $(p<0.024)$ in the GMD group and was $5.5 \%$

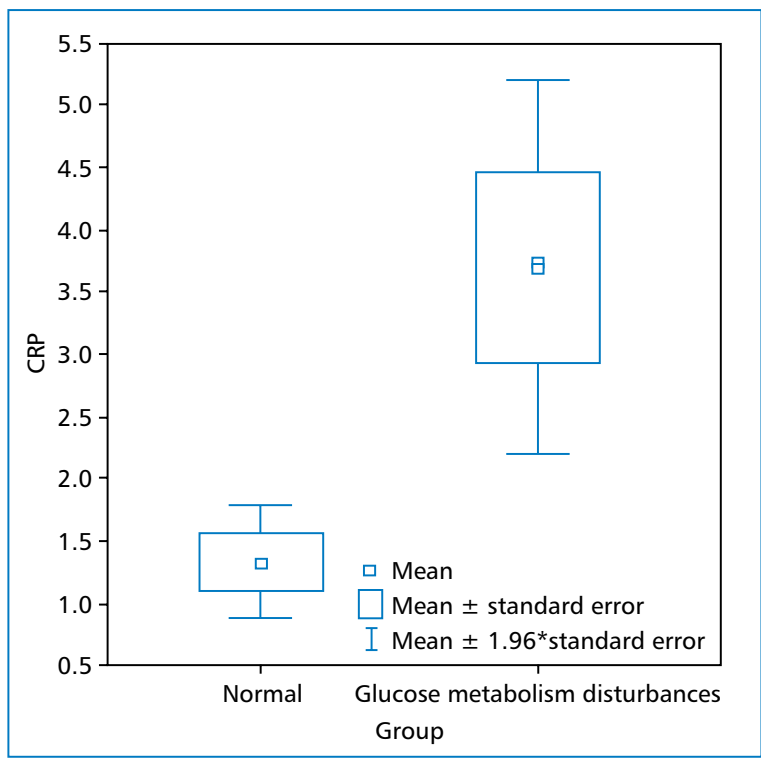

Figure 3. Mean CRP level in patients with glucose metabolism disorders (GMD) and in subjects with normal blood glucose. In the GMD group, mean CRP level was $1.3 \mathrm{mg} / \mathrm{L}$, which was significantly higher than in patients without GDM $(p<0.003)$

Table 2. The results of gastroscopy in the examined group according to the presence or absence (healthy subjects) of glucose metabolic disorders

\begin{tabular}{lcccc}
\hline Pathology & Total $(\mathbf{n}, \%)$ & Healthy subjects $(\mathbf{n}, \%)$ & Patients with GMD (n, \%) & $\mathbf{p}$ \\
\hline Helicobacter pylori & $23(25.5)$ & $8(14)$ & $15(45.5)$ & 0.001 \\
Gastritis & $8(9)$ & $4(7)$ & $4(12)$ & 0.412 \\
Gastric cancer & $1(1)$ & $0(0)$ & $1(3)$ & 0.186 \\
Gastro-esophageal reflux & $3(3)$ & $3(5)$ & $0(0)$ & 0.180 \\
Hiatal hernia & $5(5.5)$ & $3(5)$ & $2(6)$ & 0.873 \\
Gastric polyp & $1(1)$ & $1(1.7)$ & $0(0)$ & 0.444 \\
Total & $41(45.5)$ & $19(33)$ & $22(67)$ & 0.002 \\
\hline
\end{tabular}

All patients underwent gastroscopy and abnormal results were found in 41 patients $(45.5 \%$ of total study population) - in $67 \%$ in the group with GMD and $33 \%$ in the group without GDM. The most frequent pathology was Helicobacter pylori infection (25.5\%). This infection was more prevalent in the group with GDM (45\%) than in the group without GDM (14\%). In addition, gastritis, gastric cancer, gastro-esophageal reflux, hiatal hernia, and gastric polyps were found, without significant differences between the subgroups (Table 2).

\section{Discussion}

The aim of presented study was to assess the prevalence of glucose metabolism disorders (GMD) in patients with dyspepsia. Glucose metabolism disorders were diagnosed in $36.5 \%$ of patients - impaired fasting glucose in 5.5\%, impaired glucose tolerance in $22 \%$ and type 2 diabetes in $9 \%$ of patients. According to IDF from $2017,8.8 \%$ of the world's population suffers from diabetes, of whom $87-91 \%$ have type 2 diabetes [2]. In Poland, the prevalence of diabetes is on average $3.5 \%$ [1].

The results of our study indicate that the prevalence of glucose metabolism disorders among people with dyspepsia who consider themselves healthy is surprisingly high. This means that in patients with dyspepsia, diagnostic tests for diabetes should be considered. It should be emphasized that, although patients with GMD had higher mean values of random blood glucose, this value did not exceed the normal value, which did not allow for identifying GDM patients at this stage of the study. Only in $5.5 \%$ of people with GMD, fasting 
blood glucose was abnormal. It was only the OGTT result that made it possible to detect patients with GMD.

This observation confirms previous suggestions of many authors that patients should be screened for glucose metabolism disorders [3] and that the diagnosis should be based on OGTT results, not only on random blood glucose or fasting blood glucose, as their results may remain normal in patients with GMD [4].

In the examined population, pathological findings in gastroscopy, such as Helicobacter pylori infection, gastro-esophageal reflux, gastric cancer, gastoenteritis, hiatal hernia, were observed in $45.5 \%$ of patients. Taking into account only the group with GDM, these abnormalities were found in $66.5 \%$ of patients. However, when considering only organic lesions (excluding Helicobacter pylori infection), abnormal results were found only in $21 \%$. Therefore, it should be noted that dyspepsia is mainly functional in nature and that Helicobacter pylori infection is highly prevalent (it was diagnosed in as many as $45.5 \%$ of patients with GMD). In the literature, the relationship between Helicobacter pylori infection and the occurrence of metabolic syndrome has been described [5]. In a Chinese study [6], patients infected with Helicobacter pylori were characterized by a higher level of fasting blood glucose and higher BMI. Awareness of this correlation is particularly important, considering a study conducted by Mokhtare et al. who observed that effective eradication of Helicobacter pylori infection resulted in a reduction in fasting blood glucose and $\mathrm{HbA}_{1 \mathrm{c}^{\prime}}$ improvement in lipid profile and reduction in waist circumference [7]. It means that thanks to the treatment of Helicobacter pylori infection, there is a potential chance of improving the prognosis in a large group of patients participating in our study.

According to the authors' knowledge, the prevalence of GMD among patients with dyspepsia has not been assessed previously, and the problem of prevalence of dyspeptic disorders among patients with diabetes is widely discussed in the literature [8-10]. In our study, only $4.5 \%$ of diabetic patients had abnormal results of gastroscopy (except for Helicobacter pylori infection). This observation is similar to the results of other studies in which dyspepsia has been found to be predominantly functional in diabetes, and long-term poor metabolic control in diabetes leads to the development of gastroparesis $[8,9,11]$. Osicipenko et al. showed that dyspepsia affects up to $71 \%$ of patients with type 2 diabetes, and in $42 \%$, organic changes in the digestive tract were confirmed [8]. Dyspepsia was correlated with the duration of diabetes and the presence of other complications. In the study of Marizy Faria et al., the relationship between type 1 diabetes and dyspepsia was examined. Also in this study, endo- scopic examination of the upper gastrointestinal tract revealed organic changes in $34 \%$ of patients. In addition, as in our study, the association of dyspepsia with higher levels of $\mathrm{HbA}_{1 \mathrm{c}}$ was observed: in the group with $\mathrm{GMD}, \mathrm{HbA}_{1 \mathrm{c}}$ was significantly higher than in the group without GDM. The authors also link the occurrence of dyspepsia symptoms with worse glycemic control in the majority of patients $[9,10]$.

Another interesting relationship revealed by our study is the significant association of higher CRP and obesity with GMD occurrence. Patients with GMD had a significantly higher CRP level and a high BMI index. Similar correlations were found in a study by Christina et al. [12] who observed a significant relationship between hsCRP and the risk of developing diabetes: elevated hsCRP increased by $40-50 \%$ the risk of developing diabetes within 15 years of follow-up. Also in the Atherosclerosis Risk in Communities (ARIC) study, inflammation was strongly correlated with the development of diabetes regardless of other factors, including obesity [13]. Obesity is a recognized risk factor for the development of type 2 diabetes. In the ARIC study mentioned above, obese patients had a 6 -fold higher risk of developing diabetes. However, the mechanisms responsible for this phenomenon are not fully explained [14]. The relationship between obesity and elevated inflammatory parameters is so strong that obesity is considered a pro-inflammatory factor $[12,15]$. Numerous reports indicate that inflammation caused by obesity may be a link between obesity and the development of diabetes [13, 16, 17]. Hotamisligil was the first author who proposed this hypothesis, already in 1994 [18]. It is suggested that obesity leads to changes in the expression of some genes in adipocytes, which makes them produce many pro-inflammatory cytokines [15]. Inflammation causing and enhancing oxidative stress leads to dysfunction of pancreatic beta-cells [16]. Also the importance of reduced levels of adiponectin [17] - a factor that reduces inflammation and increases insulin sensitivity of tissues - in obesity is emphasized [19]. Moreover, the results of our study confirm the existence of association between glucose metabolism disorders and obesity, and an additional link intensifying these unfavorable relationships may be co-existing Helicobacter pylori infection, being another pro-inflammatory factor.

\section{Conclusions}

Over $1 / 3$ of the subjects with dyspepsia had prediabetes or diabetes; therefore, it seems that this group of patients should be screened for glucose metabolism disorders. High prevalence of GMD among patients with dyspepsia indicates potential benefits of perform- 
ing OGTT in this group of patients. Gastrointestinal symptoms may be an early manifestation of glucose metabolism disorders. There is a correlation between Helicobacter pylori infection and the presence of glucose metabolism disorders.

\section{Conflict of interest}

The authors declare no conflicts of interest in relation to this article.

\section{REFERENCES}

1. Gajewski P, Szczeklik A. Interna Szczeklika 2017. Podręcznik chorób wewnętrznych. Medycyna Praktyczna, Kraków 2017 wyd. 8.

2. IDF Diabetes Atlas. $8^{\text {th }}$ Edition. 2017, rozdział 3: 41-43

3. Samad NA, Yong PW, Mahendran K. Routine diabetes screening in blood donation campaigns. Malays J Pathol. 2015; 37(2): 137-140, indexed in Pubmed: 26277670.

4. Schwarz P. Diabetesscreening und -vorsorge. Der Internist. 2015 ; 56(10): 1124-1133, doi: 10.1007/s00108-015-3737-5.

5. Albaker W. Helicobacter pylori infection and its relationship to metabolic syndrome: Is it a myth or fact? Saudi Journal of Gastroenterology. 2011; 17(3): 165-169, doi: 10.4103/13193767.80377.

6. Yang W, Xuan C. Influence of Helicobacter pylori Infection on Metabolic Syndrome in Old Chinese People. Gastroenterology Research and Practice. 2016: 1-4, doi: 10.1155/2016/6951264.

7. Mokhtare $M$, Mirfakhraee $H$, Arshad $M$, et al. The effects of helicobacter pylori eradication on modification of metabolic syndrome parameters in patients with functional dyspepsia. Diabetes \& Metabolic Syndrome: Clinical Research \& Reviews. 2017; 11: S1031-S1035, doi: 10.1016/j.dsx.2017.07.035.

8. Osipenko MF, Zhuk EA, Medvedeva OV. Clinical characteristics of dyspepsia in patients with diabetes mellitus type 2. Ter Arkh. 2013; 85(2): 43-47, indexed in Pubmed: 23653938.

9. Faria $M$, Pavin E, Parisi $M$, et al. Dyspeptic symptoms in patients with type 1 diabetes: endoscopic findings, Helicobacter pylori in- fection, and associations with metabolic control, mood disorders and nutritional factors. Archives of Endocrinology and Metabolism. 2015; 59(2): 129-136, doi: 10.1590/2359-3997000000025.

10. Abid S, Rizvi A, Jahan F, et al. Poor glycaemic control is the major factor associated with increased frequency of gastrointestinal symptoms in patients with diabetes mellitus. J Pak Med Assoc. 2007; 57(7): 345-349, indexed in Pubmed: 17867256.

11. Tack J, Carbone F, Rotondo A. Gastroparesis. Curr Opin Gastroenterol. 2015; 31(6): 499-505, doi: 10.1097/MOG.0000000000000220, indexed in Pubmed: 26406565.

12. Parrinello $\mathrm{CM}$, Lutsey $\mathrm{PL}$, Ballantyne $\mathrm{CM}$, et al. Six-year change in high-sensitivity $\mathrm{C}$-reactive protein and risk of diabetes, cardiovascular disease, and mortality. Am Heart J. 2015; 170(2): 380-389, doi: 10.1016/j.ahj.2015.04.017, indexed in Pubmed: 26299237.

13. Duncan B, Schmidt M, Chambless L, et al. Fibrinogen, Other Putative Markers of Inflammation, and Weight Gain in Middle-aged Adults-The ARIC Study. Obesity Research. 2012; 8(4): 279-286, doi: 10.1038/oby.2000.33.

14. Lazar MA. How obesity causes diabetes: not a tall tale. Science. 2005; 307(5708): 373-375, doi: 10.1126/science.1104342, indexed in Pubmed: 15662001.

15. Sartipy P, Loskutoff DJ. Monocyte chemoattractant protein 1 in obesity and insulin resistance. Proceedings of the National Academy of Sciences. 2003; 100(12): 7265-7270, doi: 10.1073/pnas.1133870100.

16. Donath M, Shoelson S. Type 2 diabetes as an inflammatory disease. Nature Reviews Immunology. 2011; 11(2): 98-107, doi: $10.1038 /$ nri2925

17. Luft VC, Schmidt MI, Pankow JS, et al. Chronic inflammation role in the obesity-diabetes association: a case-cohort study. Diabetol Metab Syndr. 2013; 5(1): 31, doi: 10.1186/1758-5996-5-31, indexed in Pubmed: 23806173.

18. Hotamisligil GS, Spiegelman BM. Tumor necrosis factor alpha: a key component of the obesity-diabetes link. Diabetes. 1994; 43(11): 1271-1278, indexed in Pubmed: 7926300.

19. Maeda N, Shimomura I, Kishida K, et al. Diet-induced insulin resistance in mice lacking adiponectin/ACRP30. Nature Medicine. 2002; 8(7): 731-737, doi: 10.1038/nm724.

20. Gumprecht J, Młynarski W, Strojek K, et al. Zalecenia kliniczne dotyczące postępowania u chorych na cukrzycę 2018, Stanowisko Polskiego Towarzystwa Diabetologicznego. Diabetologia Praktyczna. 2018; 4(1): 5 . 